\title{
Study on the coordinated control of the bed temperature and the main steam pressure in the circulating fluidized bed boiler
}

\author{
Peng-Yuan Zhou ${ }^{1, \mathrm{a}, \dagger}$ and Pu Han ${ }^{2, \mathrm{~b}}$ \\ ${ }^{1}$ Hebei Engineering Research Center of Simulation \& Optimized \\ Control for Power Generation, Baoding, China, 071003 \\ a344746378@qq.com, bhanpu102@263.net, \\ ${ }^{\dagger}$ Corresponding author
}

\begin{abstract}
The bed temperature and the main steam pressure of the circulating fluidized bed boiler have the characteristics of nonlinearity, time variation and multi variable coupling, conventional control method is difficult to achieve the desired control effect. Therefore, based on the above problems, this paper designs a coordinated control system based on particle swarm optimization PID algorithm to the control system of bed temperature and main steam pressure. The simulation results show that the bed temperature and the main steam pressure of the system meet the control requirements, and ensure the stability of the primary air volume, which can get good control effect.
\end{abstract}

Keywords: Circulating fluidized bed boiler; The bed temperature; The main steam pressure; Coordinated control system; Particle swarm optimization PID algorithm.

\section{Introduction}

Circulating fluidized bed boiler (CFBB) developed in recent years as a new generation of international combustion boiler, having a fuel adaptability, high combustion efficiency and low NOx emissions, the desulfurization rate, good load regulation performance characteristics. Thus received wide attention, It has been widely used in electricity, heating, steam production plant [1].

But according to the survey response, there are some shortcomings in CFBB combustion technology, mainly for insufficient output, continuous operation cycle is relatively short, and the loss of the combustion exhaust gas loss is relatively high, far less than the degree of automation investment. From the perspective of control engineering considerations, CFBB usually controlled by the amount of fuel, total air volume, the amount of primary air, the secondary air flow, combustion chamber negative pressure, bed temperature, material level, and several other organic circulating ash Contact control units[1]. From the overall consideration of its control settings, there are a lot of problems, and sometimes 
cannot meet the basic requirements of the process. In particular, the combustion process is a multi-variable, nonlinear, strong coupling system, so simply using conventional control methods are difficult to achieve the desired control effect.

Control object paper studies the main steam pressure and the bed temperature of CFBB combustion system, main steam pressure of CFBB is mainly through the amount of fuel control, the bed temperature mainly by the amount of fuel and primary air volume control, and therefore the main steam pressure and beds temperature is a very strong coupling effects, so the conventional control is difficult to achieve the desired control effect. At present, one of the most commonly used method is the main steam pressure control, according to the experience in accordance with the best wind coal ratio control, while adjusting the primary air volume to ensure that the bed temperature in the specified range. In order to ensure the safety of CFBB combustion, on the bed temperature control has a very strict requirements, the general control in the 850 950 DEG C, low not only will decreased thermal efficiency, and can make the boiler combustion instability, even boiler flameout; too high will reduce the furnace desulfurization efficiency, nitrogen oxide production increased greatly, also easy to cause the coking, destruction of the running state of CFBB, caused the accident [2]. Practice shows that the control method is less effective, it needs more human control, low automation, it is difficult to ensure that the bed temperature control to a reasonable range.

In this paper, we try to design a new control scheme to realize the control of main steam pressure and bed temperature. In the choice of controller, the optimal control parameters are determined by the method of particle swarm optimization, which can solve the problems such as nonlinear, time varying and multi variable of control object. And on the basis of single loop control, the coordination control system of main steam pressure and bed temperature is established based on the field experience, which can effectively solve the coupling effect between the two.

\section{Fuel-Bed Temperature Control System}

The dynamic characteristics of the controlled object in the bed temperature can be expressed by the following transfer function [2]:

$$
G_{c T}=\frac{(1+\alpha s)}{\left(T_{e 1} s+1\right)\left(T_{e 2} s+1\right)} K_{e} e^{-\tau s}
$$

(1) Through the identification of the field data, it is found that the $K_{\varepsilon}, T_{\varepsilon 1}$, ${ }_{\varepsilon 2}, \tau$ and $\alpha$ in the above are also changed with the different working conditions of the boiler. When the boiler load changes in $25 \%$ 100\%, the 
variation range of the above parameters is: $K_{\varepsilon}: 5 \sim 8 ; T_{\varepsilon 1}, T_{e 2}$ : $100 \sim 200 \mathrm{~s} ;{ }^{\tau}: 60 \sim 120 \mathrm{~s} ; \alpha$ :8 12.

\section{Primary Air - Bed Temperature Control System}

By The dynamic characteristics of the controlled object can be expressed as the following transfer function in the primary air flow disturbance [2]:

$$
G_{G T}=\frac{(1+\beta s)}{\left(T_{f 1} s+1\right)\left(T_{f 2} s+1\right)} K_{f}
$$

(2) When the boiler load changes in the range of $25 \%$ 100\%, the variation range of the above parameters is: $K_{f}: 0.5 \sim 1.5 ;{ }_{f 1},{ }_{f 2}: 100 \sim 150 \mathrm{~s} ; \beta^{2}: 2 \sim 5 \mathrm{~s}$.

\section{Fuel - Bed Pressure Control System}

Under the disturbance of fuel quantity, the dynamic characteristics of the main steam pressure controlled object can be expressed as follows [2]:

$$
G_{c P}=\frac{(1+\alpha s)}{\left(T_{p 1} s+1\right)\left(T_{p 2} s+1\right)\left(T_{P 3}+1\right)\left(T_{e 1} s+1\right)\left(T_{e 2} s+1\right)} K_{p} e^{-s s}
$$

(3) When the boiler load changes in the range of $25 \%$ 100\%, the variation range of the above parameters is: $K_{p}: 0.2 \sim 0.5 ;{ }_{p 1},{ }_{p 2}: 100 \sim 150 \mathrm{~s} ;{ }_{p 3}: 50 \sim 100 \mathrm{~s}$.

\section{Bed Temperature Main Steam Pressure Coordinated Control}

According to the manual operation experience, generally in the CFBB in normal operation, the primary air volume remained unchanged, mainly through regulating the amount of fuel to control the main steam pressure. Change in fuel content will affect the bed temperature, when the bed temperature is too high or too low (above 950 degrees or below 850 degrees Celsius), you need to change the primary air to adjust the bed temperature to the appropriate temperature. According to the idea of coordinated control, the coordinated control system of main steam pressure and bed temperature is designed. 


\subsection{Coordinated Control System}

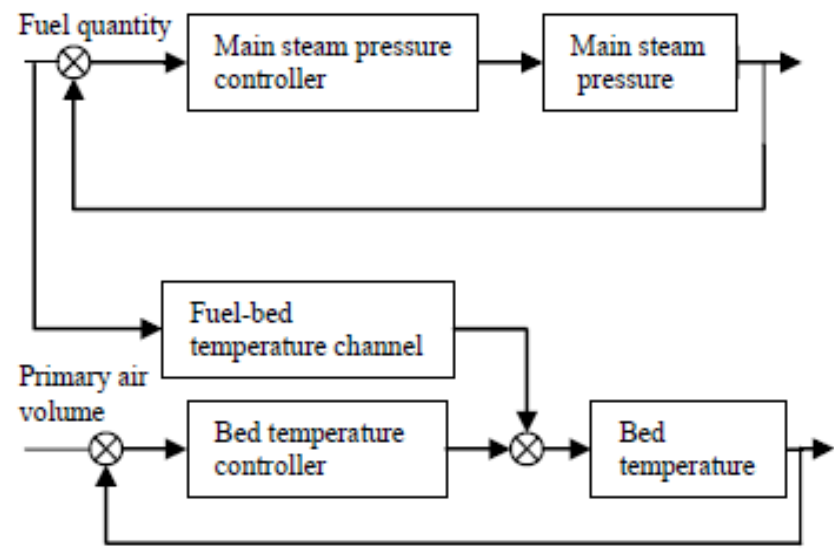

Fig.1 Bed temperature and main steam pressure control system

As shown in Fig.1, control system mainly by the amount of fuel to control the main steam pressure, fuel flow and main steam pressure channel characteristics of the object changes due to the relatively large, ordinary PID controller can not adapt to the system of nonlinear and time-varying, so here with particle swarm algorithm of self tuning PID controller as the main steam pressure controller. When the load changes or the main steam pressure set value changes, the main steam pressure controller to maintain the balance of the system by adjusting the amount of fuel. Changing the amount of fuel will cause the bed temperature changes, in order to maintain the stability of the bed temperature system, where the primary air volume used as the control variable of the bed temperature. However, in order to ensure the stability of fluidized bed, it should be as far as possible to ensure the stability of the primary air volume. So comprehensive consider these two aspects, usually the bed temperature kept in a reasonable range (usually set 850 to $950 \mathrm{DEG} \mathrm{C}$ ). When the bed temperature in this range, the controller does not need to be adjusted, when the temperature exceeds the range, the bed temperature is maintained in a reasonable range by adjusting the parameters. When the bed temperature is stable, the bed temperature controller will not continue to adjust, until the bed temperature exceeds the reasonable range. Because of the change of the characteristics of the object of the primary air and bed temperature control channel is relatively small, and it can not be adjusted frequently, so the conventional PID control can be used. 


\subsection{Simulation Analysis}

With the aid of MATLAB, the design of the coordinated control system is simulated.

Using coordinated control to control the system, in the case of normal operation, the fuel-main steam pressure channel is controlled by the parameter

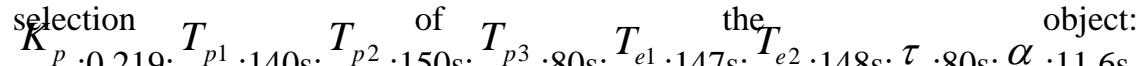
.111.6s The fuel-bed temperature chapnel is controlled with the parameter selection of the object: $K_{\mathrm{e}}: 5.84 ;{ }_{\mathrm{el}}: 147 \mathrm{~s} ;{ }_{e 2}: 148 \mathrm{~s} ;{ }^{\tau}: 80 \mathrm{~s} ;{ }^{\alpha}: 11.6 \mathrm{~s}$. The primary air-bed temperature channel controlled object parameters are:

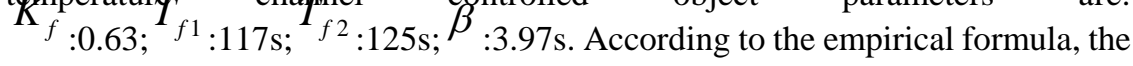
parameters $\mathcal{K}_{i 1}^{\text {f }}$ the tyo PID $K_{p 2}^{\text {controllers are respectively: }}$ the range of $850 \sim 950{ }^{\circ} \mathrm{C}$, in order to avoid the bed temperature setting range boundaries frequent oscillations cause the controller to turn on or off frequently, so the bed temperature controller coupled with some rules, such as the control of the controller as shown in Fig 2. When the temperature in the range of $850 \sim$ $950{ }^{\circ} \mathrm{C}$, the controller does not adjust the bed temperature, when the temperature is out of range, less than $850{ }^{\circ} \mathrm{C}$, the bed temperature is set to $870{ }^{\circ} \mathrm{C}$; greater than $950{ }^{\circ} \mathrm{C}$, the bed temperature is set to $930{ }^{\circ} \mathrm{C}$. At the same time start the controller, the bed temperature is adjusted to the set value, when the bed temperature stabilized, turn off the controller, until once again exceed $850 \sim 950{ }^{\circ} \mathrm{C}$ start again. The bed temperature setpoint and range over the left margin of $20{ }^{\circ} \mathrm{C}$, avoid frequent start controller, reducing the primary air volume changes.

Control effect as shown in fig3 and fig4: 


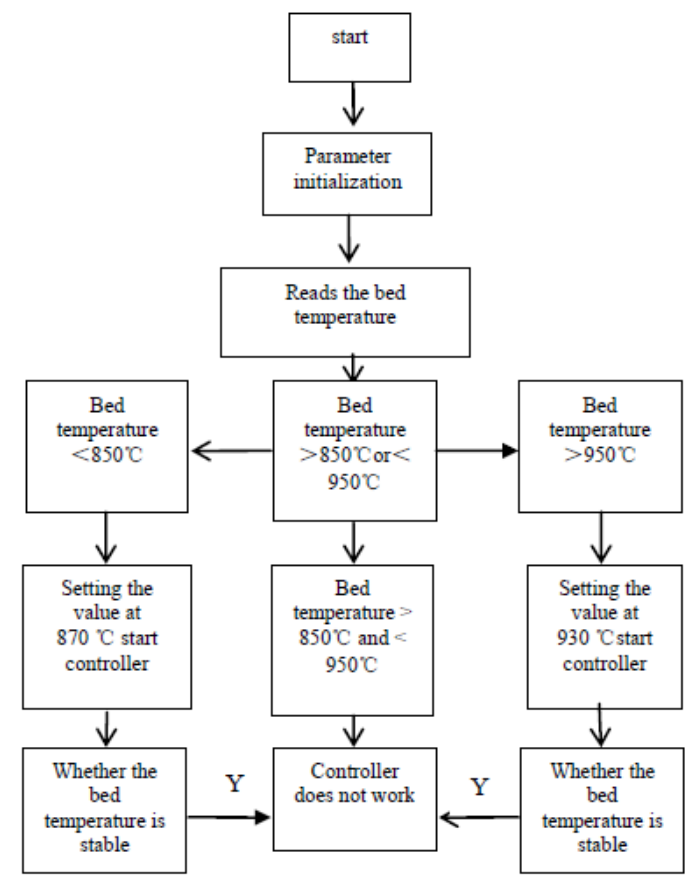

Fig.2 Coordination control rules

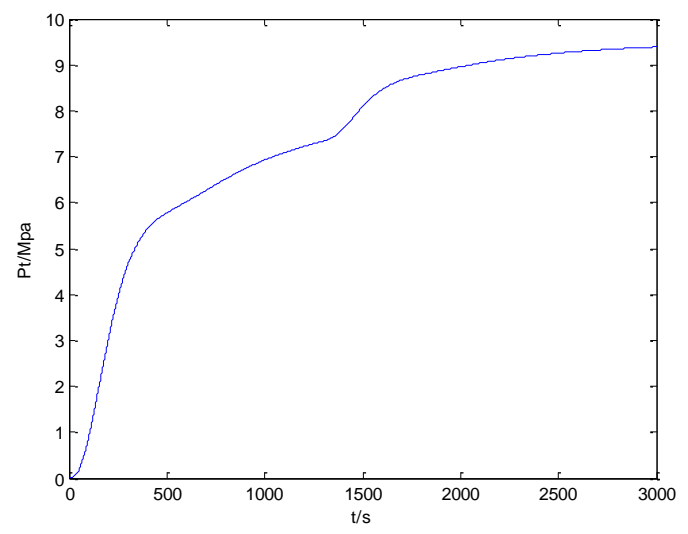

Fig.3 Response curve of main steam pressure 


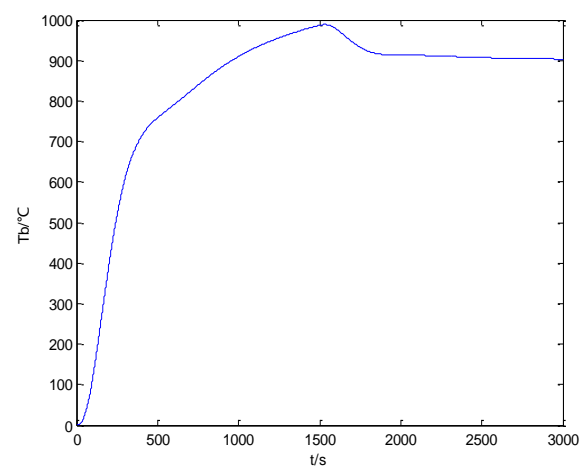

Fig.4 Response curves of bed temperature

The optimal parameters of the fuel-main steam pressure channel's PID were determined by MATLAB: $T^{i 1}=408.01 ;{ }^{K 1}=1.1014$.

From the two pictures can be seen, based on particle swarm self-tuning PID controller coordinated control system is ideal for the control of main steam pressure and bed temperature, the changes in working conditions will not control produced great influence, the change characteristics of the object also has very good adaptability. In order to meet the load requirements, the amount of fuel has been increased, the main steam pressure increases, around 1400s, the bed temperature due to increased amount of fuel exceeds $950^{\circ} \mathrm{C}$, thereby triggering the primary air-bed temperature controller working to set the setpoint to $930^{\circ} \mathrm{C}$. As can be seen from fig4, the bed temperature in the 1550 s or so back to normal, the controller to close the work.

\section{Summary}

In this paper, the control system of bed temperature and main steam pressure is designed on the basis of field control experience, based on the single loop control, using the PID algorithm of particle swarm optimization. Coordinated control system can ensure the bed temperature is in a reasonable range, maintain a steady primary air volume, control main steam pressure by fuel. Only when the bed temperature exceeds the specified range, the primary air volume control is changed. The feasibility and effectiveness of the control system is verified by simulation experiments.

\section{Acknowledgment}

I would like to extend my sincere gratitude to my tutors Han $\mathrm{Pu}$ and Wang Dongfeng. For their instructive advice and useful suggestions on my thesis. 
Special thanks should go to my friends who have put considerable time and effort into their comments on the draft. Last my thanks would go to my beloved family for their loving considerations and great confidence in me all through these years

\section{References}

[1] Sun Jian. Study on the characteristics and modeling of the combustion system of large circulating fluidized bed boilers [D]. North China Electric Power University (Beijing), 2010. In Chinese.

[2] Wang Yanghua. Study on the intelligent control of combustion in circulating fluidized bed boiler [D]. Hunan University of Technology, 2013. In Chinese.

[3] Tao Yonghua. New PID control and its application [M]. Beijing: Mechanical Industry Press, 2002. In Chinese.

[4] Hu Shousong. The principle of automatic control (Fourth Edition) [M]. Beijing: Science Press, 2001. In Chinese.

[5] Edward B, Magrab, Li Xinye, Hu Zhiqi, et al. MATLAB principle and engineering application $[\mathrm{M}]$. Beijing: Publishing House of electronics industry, 2002. In Chinese.

[6] Wang Shuqing et al. Industrial process control engineering [M]. Beijing: Chemical Industry Press, 1998. In Chinese.

[7] H. Yuchun, L. Donghai and T. Wen, "Design of the PID controller for circulating fluidized bed boiler combustion system," Control Conference (CCC), 2012 31st Chinese, Hefei, 2012, pp. 4580-4585.

[8] Y. Guili, G. Mi and L. Zhongfu, "Linear active disturbance rejection decoupling control of circulating fluidized bed boiler' combustion system," 2013 25th Chinese Control and Decision Conference (CCDC), Guiyang, 2013, pp. 113-118. 